\title{
Surface Modification of Polyhydroxyalkanoates by I on Implantation. Characterization and Cytocompatibility Improvement
}

\author{
Xiaoyun Chen, Xiongfei Zhang, Ya Zhu, ${ }^{*}$ Jizhong Zhang, ${ }^{*}$ and Ping $\mathrm{HU}^{\dagger}$ \\ Institute of Polymer Science \& Engineering, Tsinghua University, Beijing 100084, P. R. China \\ *Department of Materials Science \& Engineering, Tsinghua University, Beijing 100084, P. R. China
}

(Received August 19, 2002; Accepted November 1, 2002)

\begin{abstract}
Surface modification of three species of PHAs, PHB, P(HB-co-HV) and P(HB-co-HH), were carried out by $40 \mathrm{keV} \mathrm{C}^{+}$ion implantations at four different doses, $1 \times 10^{12}, 1 \times 10^{13}, 1 \times 10^{14}$, and $1 \times 10^{15}$ ions cm $^{-2}$. Remarkable changes between the pristine samples and the implanted samples were observed for the FT-IR and XPS spectra. Fibroblast culture was conducted to investigate the surface biocompatibility changes caused by the implantation of $\mathrm{C}^{+}$. From the results of the MTT colorimetric test and the cell morphology observation assessed by SEM, FI and Confocal Laser Scanning Microscopy (CLSM), there were several evidence that the cytocompatibility of the films were improved by ion implantation and the best cytocompatibility was achieved at the ion dose of $1 \times 10^{12}$ for all the three species of PHAs. Possible explanation is given by correlating the cell adhesion figures with the chemical and physical changes in the modified surfaces. Results show that the PHAs modified by ion implanting could be a promising family of biomaterials for tissue engineering.

KEY WORDS Polyhydroxybutyrate (PHB) / Polyhydroxyalkanoates (PHAs) / Surface Characterization / Ion Implantation / Cytocompatibility /
\end{abstract}

Polyhydroxyalkanoates (PHAs) are a class of polyesters mainly synthesized by several kinds of bacteria. ${ }^{1,2}$ Because of their thermal plasticity, biocompatibility and biodegradability, there have been many examples of PHAs' applications in the medical and agricultural fields. Its application as scaffold materials in tissue engineering and drug carrier in controlled release is getting high impetus these days. ${ }^{3}$ To tailor the surface properties to some specific application, several surface modification methods such as treatment with $\mathrm{NaOH}$ and lipases, ${ }^{4}$ plasma treatment ${ }^{5}$ and ${ }^{60} \mathrm{Co} \gamma$-radiation ${ }^{6}$ have been investigated.

Ion implantation has long been recognized as a useful method to improve the surface property of metals and semiconductors without significantly altering the materials' bulk property. A plasma-based ion implantation (PBII) technique is used for surface modification of materials and for improving surface properties. ${ }^{14}$ In recent years, ion implantation has been applied to the surface modification of polymers to improve blood compatibility $^{15-17}$ and tissue compatibility. ${ }^{18}$

Many researches undertaken up to now focus on the wettability, ${ }^{8,9}$ conductivity ${ }^{10,11}$ and tribological properties $^{7,12,13}$ change of the implanted polymer surfaces. The results show that ion implantation is a very effective method of surface modification in these fields. In recent years, progress of research on the surface modification of polymers by ion implantation is expected in the biomedical field for improving biocompatibility and for conveying biofunction abilities such as antibacterial, cell-orientation and selective adhesion properties. ${ }^{18-20}$

The $\mathrm{C}^{+}$implantation has been applied to several polymers, for example, $\mathrm{PTFE}^{9}$ and $\mathrm{PET}^{13}$ to improve their surface properties. In this study, we investigated the surface modification of PHAs-Polyhydroxybutyrate (PHB), poly(hydroxybutyrate-co-hydroxyvalerate) $(\mathrm{P}(\mathrm{HB}-\mathrm{co}-\mathrm{HV}))$, and poly(hydroxybutyrate-cohexanoate) $(\mathrm{P}(\mathrm{HB}-\mathrm{co}-\mathrm{HH}))$ via different dose of $\mathrm{C}^{+}$ implantation. In addition, the modified polymer films were investigated using 3T6 fibroblasts cultures for the assessment of the cytocompatibility based on their ability to promote cell adhesion and proliferation.

\section{EXPERIMENTAL}

\section{Sample Preparation}

$\mathrm{PHB}, \mathrm{P}(\mathrm{HB}-\mathrm{co}-\mathrm{HV}), \mathrm{P}(\mathrm{HB}-c o-\mathrm{HH})$ were all provided by the Department of Biological Science and Biotechnology of Tsinghua University and used without further purification. They were first dissolved in chloroform and then cast onto petri dishes. The petri dishes were kept in room temperature and covered by glass plates to control the evaporation rate of chloroform. The thickness of each film was about $0.1 \mathrm{~mm}$. 


\section{Ion Implantation}

The PHB, $\mathrm{P}(\mathrm{HB}-\mathrm{co}-\mathrm{HV}), \mathrm{P}(\mathrm{HB}-\mathrm{co}-\mathrm{HH})$ films were irradiated with $40 \mathrm{keV} \mathrm{C} \mathrm{C}^{+}$at four different ion dose, $1 \times 10^{12}, 1 \times 10^{13}, 1 \times 10^{14}$, and $1 \times 10^{15}$ ions cm $\mathrm{cm}^{-2}$. The ion current were kept below $1.3 \mu \mathrm{A} \mathrm{cm}^{-2}$ to minimize the thermal effect ion implantation might cause. The pressure in the implanter target chamber was kept below $3 \times 10^{-3} \mathrm{~Pa}$.

\section{FTIR-ATR Analysis}

Fourier transform infrared-attenuated total reflection (FTIR-ATR) method was employed to investigate the outermost and subsurface regions of the pristine and implanted samples. The spectra were recorded with a NICOLET560 spectrophotometer equipped with an ATR attachment.

\section{XPS Analysis}

The elemental composition of the sample surfaces were analyzed with XPS (PHI-5300) employing Al-K $\alpha$ $\mathrm{X}$-Ray sources $(1486 \mathrm{eV})$ radiation. The pressure of the chamber was $<10^{-7} \mathrm{~Pa}$. The multi-peak fitting of the C1s spectra obtained was conducted with software of the Origin 7.0 with a Peak-fitting-module.

\section{SEM Investigation}

The morphology of the samples was examined by scanning electron microscopy (SEM), S-450, Hitachi.

\section{CLSM}

The three-dimensional cells' constructs and density were obtained with confocal laser scanning microscopy (CLSM), Radiance 2100, Biorad.

\section{Cell Cultures}

Cell Culture and Co-Culture with Material. The PHAs films were cut into $1 \times 1 \mathrm{~cm}$ squares, and then sterilized by $\gamma$-ray irradiation ( $2 \mathrm{Mrad}$ ). The commercial 3T6 fibroblasts (Shanghai Institute of Biochemistry and Cell Biology-Chinese Academy of Sciences) were seeded onto the pristine and implanted films in 24-well plates at a concentration of $7 \times 10^{5} \mathrm{cells} \mathrm{cm}^{-2}$ in Dulbecco's Modified Eagle Medium (DMEM) supplemented with 10\% Fetal Bovine Serum (FBS). The cultures were maintained in a humidified atmosphere consisting of $95 \%$ air and $/ 5 \% \mathrm{CO}_{2}(\mathrm{v} / \mathrm{v})$ at $37^{\circ} \mathrm{C}$, and routinely examined using a light microscopy (Olympas IX70/IX50, Tokyo, Japan).

MTT Assay. MTT assay ${ }^{21,22}$ was conducted to the cell density on the sample films after $24 \mathrm{~h}$ 's culture. $\quad 100 \mu \mathrm{L}$ of MTT (3-[4,5-dimethylthiazol-2yl]-2,5-diphenyltetrasodium bromide) (Merck) solution (5 $\mathrm{mg} \mathrm{mL}^{-1}$ MTT powder in phosphate buffer saline, sterilized through a $0.2-\mu \mathrm{m}$ filter) were added into each well and incubated at $37{ }^{\circ} \mathrm{C}$ for $4 \mathrm{~h}$ to allow the yellow dye to be transformed into blue formazan crystals. The plates were shaken for $30 \mathrm{~min}$ to ensure the complete dissolution of the formazan. Light absorbance of these samples was measured at $550 \mathrm{~nm}$ on an Ultrospec 3100 pro UV/visible Spectrophotometer (Biochrom Ltd., England).

Cellular Morphology Observations. Cultures of 3T6 cells grown in 24-well plates were washed twice in cold PBS (PH 7.2), fixed with freshly prepared 2.5\% glutaraldehyde in $0.1 \mathrm{M}$ PBS (PH 7.2) for $30 \mathrm{~min}$ at room temperature, and permeabilized with $0.2 \%$ Triton X-100 in PBS for 10 min. $^{23}$ Then the fixed 3T6 cells were stained by Propidium Iodide (PI, Sigma), examined by fluorescence microscopy (Nikon E995) and confocal laser scanning microscopy (Bio-Rad, Ridiance 2100, AG-2Q). ${ }^{24,25}$

Cells fixed in a general way ${ }^{26}$ were also examined by scanning electron microscopy (KYKY2000).

\section{RESULTS AND DISCUSSION}

\section{FTIR-ATR}

We can see from Figure 1 that there are some significant differences between the spectra of the pristine PHBV samples and the samples with dose of $1 \times 10^{12}$ ions $\mathrm{cm}^{-2}$ and $1 \times 10^{13}$ ions $\mathrm{cm}^{-2}$, for example, the rising of the peaks at the wavelength around the relative height of peaks at $920 \mathrm{~cm}^{-1}$, the formation of new peaks at 1532 and $1600 \mathrm{~cm}^{-1}$. Many of these changes cannot be definitely ascribed to a certain change in the molecular structure because of the fact that the IR spectra of a polymer is determined not only by its molecular structure but also its microstructure such as its crystallization.

The changes around $2800-3000 \mathrm{~cm}^{-1}$ might be

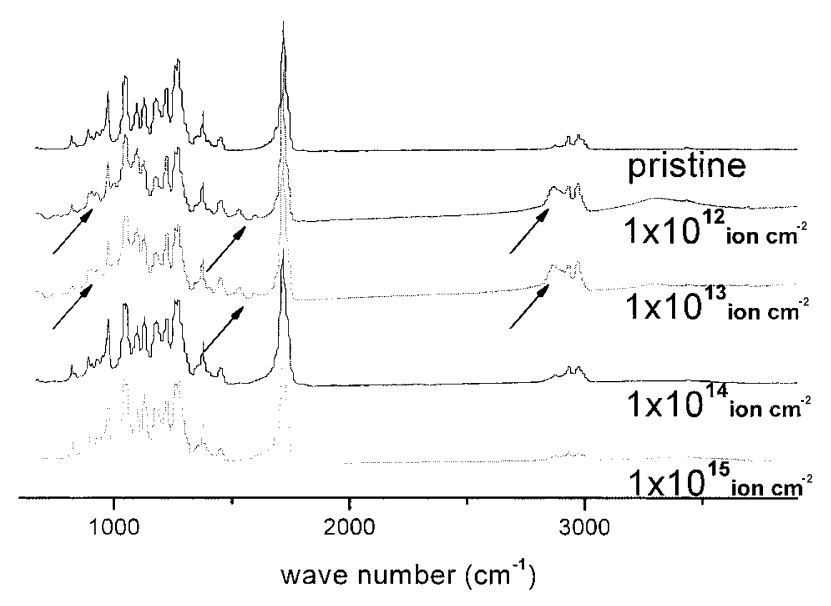

Figure 1. Result of the FTIR-ATR spectra of PHBV films. (Arrows on the graph indicate the most obvious change of absorbance) 
caused by the formation of hydronated amorphous carboneous layer $(\mathrm{a}-\mathrm{C}: \mathrm{H})^{27}$ during the implantation or after the implanted samples were exposed to air. The formation of new peaks around 1532 and $1600 \mathrm{~cm}^{-1}$ might indicate the formation of double bonds or conjugated cyclic structures. It seems that there exists some correlation between those two changes mentioned above from Figure 1 but further investigation is needed to determine whether a newly formed structure caused these changes or they are caused by different reasons.

It is interesting to observe that those two changes mentioned above almost disappeared with the increase of ion dose, and the spectra of PHBV sample films with ion dose $1 \times 10^{14}$ ions $\mathrm{cm}^{-2}$ and $1 \times 10^{15}$ ions $\mathrm{cm}^{-2}$ actually resemble the spectrum of pristine PHB. The FTIRATR spectra of the PHBV and PHBH films also showed the same trend (not shown here).

It seems there exists a threshold around $1 \times 10^{12}$ ions $\mathrm{cm}^{-2}$ and $1 \times 10^{13}$ ions $\mathrm{cm}^{-2}$. Such kind of a threshold caused by ion implantation has also been observed, though not necessarily in IR spectra, in some other investigation of ion implantation of polymers. ${ }^{28,29}$ Considering the uniqueness of the ion implantation process, ${ }^{30}$ we can make a possible explanation for this phenomenon. When the ion dose is not very high, most of the ions will react with the PHB materials and form a hydronated carboneous layer. There will be such a threshold of ion dose beyond which the ions implanted will not react with the polymer itself and instead it will first react with the carboneous layer. The hydrogen atoms will be emitted from the surface in the form of some volatile small molecules such as $\mathrm{H}_{2}$ or $\mathrm{H}_{2} \mathrm{O}$. The previously formed hydronated will be turned into amorphous carbon layer at the high ion fluence, which will not be detected in ATR spectra.

What should also be noted is that the typical analysis depth of FTIR-ATR is several microns while the

ion stopping range for $\mathrm{C}^{+}$in our experiment was about $0.15 \mu$ as estimated with the TRIM $2000,{ }^{31}$ so some remarkable changes in the surface might not be sensitively reflected in the FTIR-ATR spectra.

\section{XPS Analysis}

In order to investigate the detailed changes in the outmost layer of the samples caused by the implantation of $\mathrm{C}^{+}$, XPS analysis were employed because of its ability to reveal the chemical states of elements on the polymer surfaces. The multi-peak fitting was conducted with the Origin Pro 7.0 with a Peak Fitting Module to find out the detailed information about carbon in different chemical states. The $\mathrm{C} 1 \mathrm{~s}$ of the pristine PHB was resolved into four elementary peaks. The binding energy of various $\mathrm{C} 1 \mathrm{~s}$ peaks are follows: $\mathrm{C}-\mathrm{C} / \mathrm{C}-\mathrm{H}: 285.0 \mathrm{eV}$, $\mathrm{C}^{*}-\mathrm{C}=\mathrm{O}$ (carbon next to the carbonyl), $\mathrm{C}-\mathrm{O}: 286.9 \mathrm{eV}$, $\mathrm{C}=\mathrm{O}: 289.2 \mathrm{eV}$, and amorphous C: $284.6 \mathrm{eV}^{2,8,32,33}$

From Figure 2 and Table I, we can get a clear picture of how carbon of different chemical states is altered by the $\mathrm{C}^{+}$implantation. It can be clearly seen that with the increase of ion dose (1) the $\mathrm{C} / \mathrm{O}$ ratio kept increasing, which was caused by two reasons: the corporation of carbon ions into the polymers and the elimination of small molecules containing oxygen. Because the surface composition change caused by the incorporation of the implanted carbon ions is very small, we can come to the conclusion that in the process of the ion

Table I. The surface compositions, (in atoms\%), of the pristine $\mathrm{P}(\mathrm{HB}-\mathrm{HV})$ samples and samples implanted with different ion

\begin{tabular}{lccrrr}
\multicolumn{7}{c}{ doses } \\
\hline Ion dose $\left(\right.$ ions cm $\left.^{-2}\right)$ & \multicolumn{1}{c}{0} & $1 \times 10^{12}$ & $1 \times 10^{13}$ & $1 \times 10^{14}$ & $1 \times 10^{15}$ \\
\hline $\mathrm{C} / \mathrm{O}$ ratio & 2.11 & 2.21 & 2.36 & 2.77 & 6.35 \\
$\mathrm{C}-\mathrm{C} / \mathrm{C}-\mathrm{H}$ & 32.46 & 37.42 & 39.41 & 48.22 & 57.89 \\
$* \mathrm{C}-\mathrm{C}=\mathrm{O}$ & 22.74 & 19.27 & 14.56 & 11.81 & 0.22 \\
$\mathrm{C}-\mathrm{O}$ & 24.01 & 22.93 & 26.53 & 22.60 & 18.17 \\
$\mathrm{C}=\mathrm{O}$ & 20.79 & 20.38 & 18.80 & 13.21 & 3.35 \\
Amorphous $\mathrm{C}$ & - & - & 0.70 & 4.16 & 20.37 \\
\hline
\end{tabular}

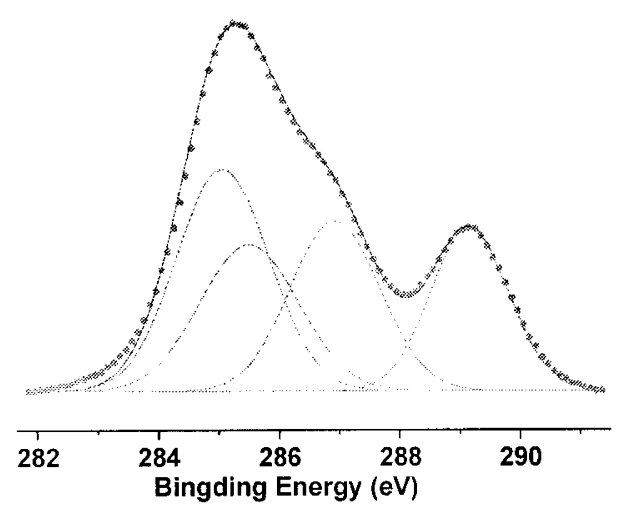

a

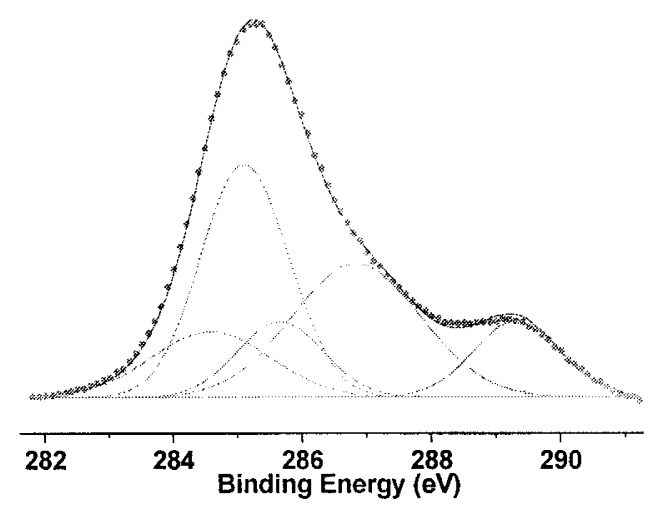

b

Figure 2. C1s spectra of (a) pristine PHBV films, (b) implanted PHBV films at the ion dose of $1 \times 10^{13}$ ions $\mathrm{cm}^{-2}$, and (c) implanted PHBV films at the ion dose of $1 \times 10^{14}$ ions $\mathrm{cm}^{-2}$ (with curve fitting results). 

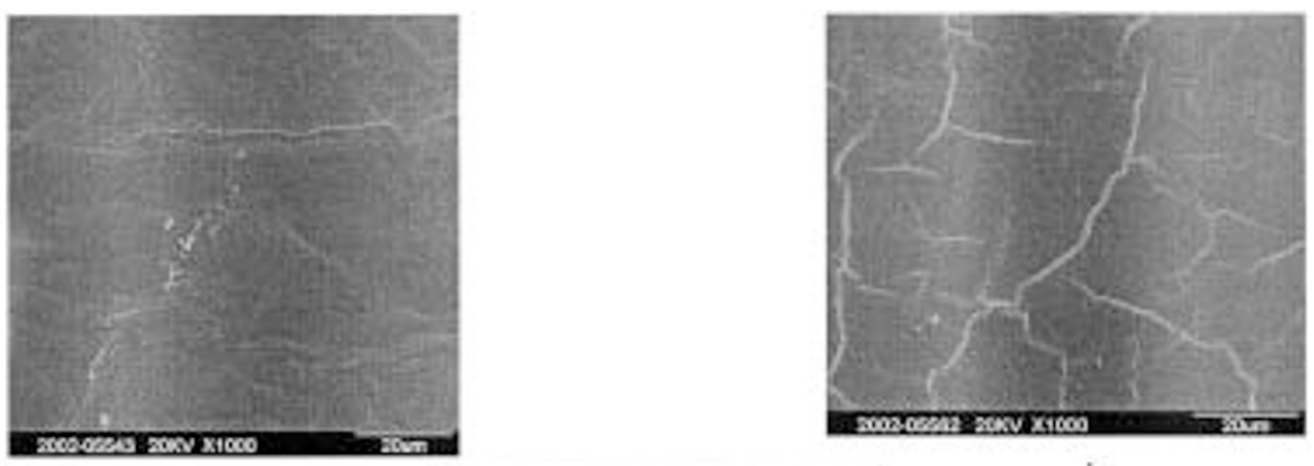

a

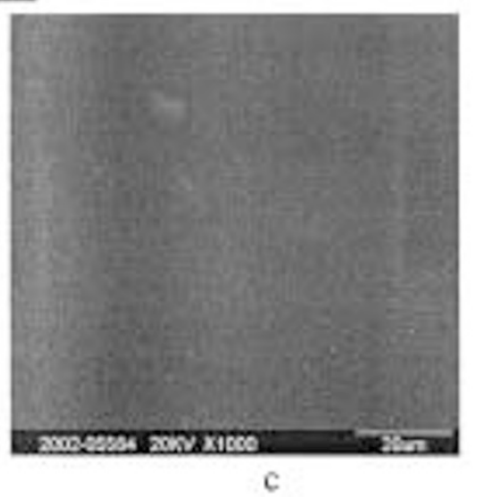

b

Figure 3. SEM micrographs of (a) pristine $\mathrm{P}(\mathrm{HB}-\mathrm{co}-\mathrm{HH})$ samples, and samples with dose of (b) $1 \times 10^{14}$ ions $\mathrm{cm}^{-2}$, (c) $1 \times 10^{15}$ ions $\mathrm{cm}^{-2}$.

implantation some volatile species containing $\mathrm{O}$ such as $\mathrm{O}_{2}, \mathrm{H}_{2} \mathrm{O}$ and $\mathrm{CO}_{2}$ will be formed and diffuse into the surroundings. And thus a hydronated carboneous layer will be formed.

(2) the $\mathrm{C}-\mathrm{C} / \mathrm{C}-\mathrm{H}$ percentage kept increasing, which indicated that $\mathrm{C}^{+}$ions were partly incorporated into the polymer chains.

(3) the percentage of $\mathrm{C}=\mathrm{O}$ kept decreasing. The oxygen content decrease is caused by the formation of volatile species containing oxygen and the possible formation of $\mathrm{C}-\mathrm{O}-\mathrm{C}$ bond.

(4) the $\mathrm{C}-\mathrm{O}$ composition did not have a strong correlation with the ion dose.

More detailed investigation will be undertaken to gain a insight of how the mechanism lying behind such as the $\mathrm{sp}^{2}, \mathrm{sp}^{3}$ content change, the various structure of carboneous layer.

\section{SEM}

Several studies of polymer surface modification by ion implantation show that the surface morphology will undergo remarkable changes after the implantation..$^{9,34}$

From Figure 3, no such significant surface restructuring can be observed. The pristine film's surface was smooth overall due to the controlled evaporation process and the small creases might be caused by the contraction or inner strain of the film. For samples surface implanted with $\mathrm{C}^{+}$fluence lower than $1 \times 10^{14} \mathrm{~cm}^{-1}$, the overall surface morphology almost remains the same while the creases in the pristine samples look more standing-out; which might be caused by

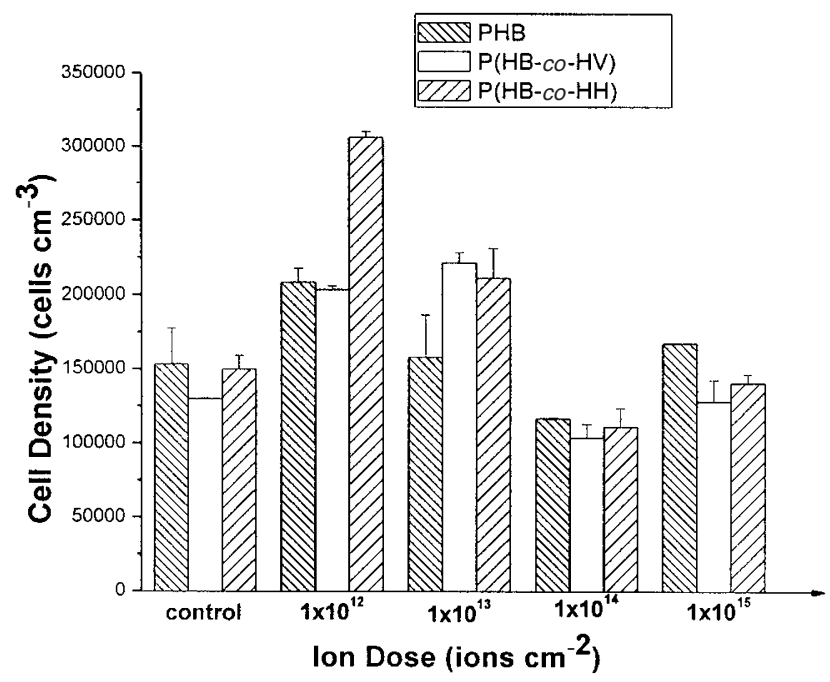

Figure 4. Effect of ion implantation treatment on the viability of cells grown on $\mathrm{PHB}, \mathrm{P}(\mathrm{HB}-\mathrm{co}-\mathrm{HV})$ and $\mathrm{P}(\mathrm{HB}-\mathrm{co}-\mathrm{HH})$. Statistical analysis performed by ANOVA showed $\mathrm{P}$ values in all data are smaller than 0.05 .

the peeling-off of the margin area of the crease; but for films with a $1 \times 10^{15} \mathrm{~cm}^{-1}$ implantation dose, a quite smooth surface was observed, which indicated that the large ion dose might has an effect of smoothing.

\section{MTT Assay and Cell Morphology Observation}

Figure 4 shows the overall change of cell density on the sample surfaces depending on ion doses. For all three species of PHAs, the cell adhesion enhancement is obvious at low dose modified surfaces but then the cell density dropped to a value lower than the control. 

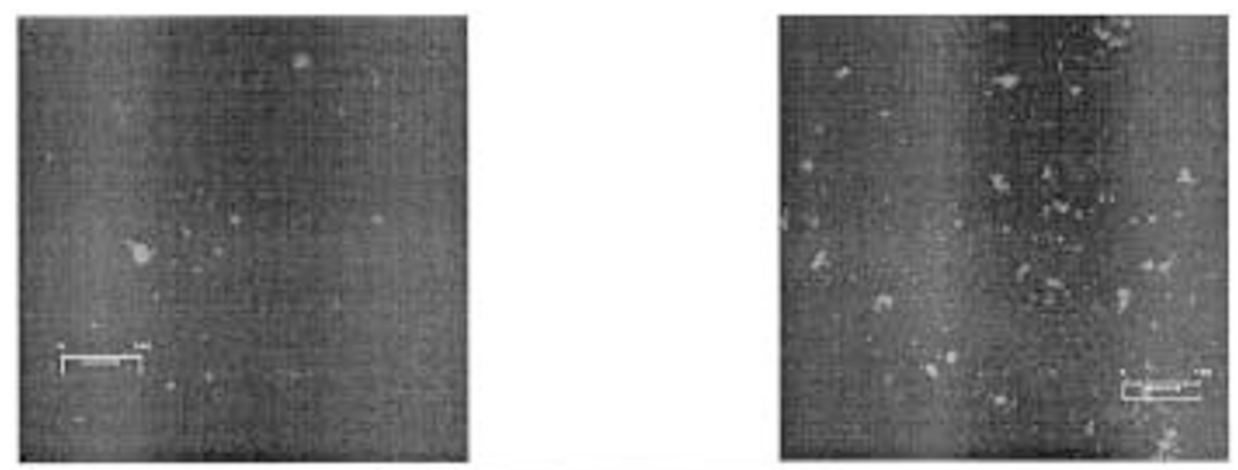

a

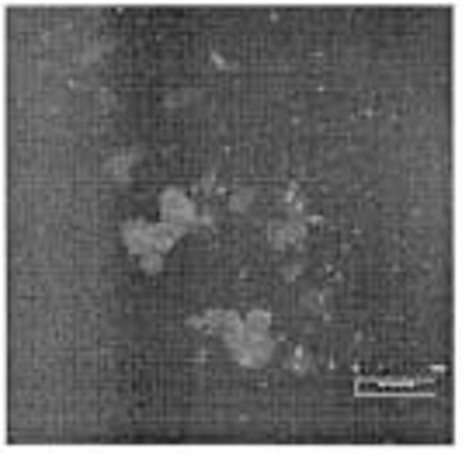

b

$c$

Figure 5. Confocal Laser Scanning Microscopy (CLSM) of mouse 3 T6 cells stained by PI on (a) pristine P (HB-co-HH) sample surface, (b) samples with an ion implantation dose of $1 \times 10^{12}$ ions $\mathrm{cm}^{-2}$. Bars on the pictures stand for $100 \mu \mathrm{m}$, and (c) samples of the $24 \mathrm{~h}$ culture with an ion implantation dose of $1 \times 10^{12}$ ions $\mathrm{cm}^{-2}$. Bars on the pictures stand for $100 \mu \mathrm{m}$.

After that the cell density rises again. From SEM results discussed above, we know that the surface morphology also goes through some small changes at different ion doses. Since the cell adhesion is closely related to the smoothness of the surface, the MTT result could only show the overall trend of the surface cell adhesion changes. The newly formed hydronated carboneous layer might cause the initiatory improvement. From the result of XPS and FTIR-ATR, we can see that the original surface composition was only partially changed at low ion dose and as the ion dose increasing the newly formed layer became the foremost layer, which was irradiated with $\mathrm{C}^{+}$ions and might be damaged. This might be the cause of the subsequent decrease in result of MTT assay.

After $24 \mathrm{~h}$ culture in media, the mouse $3 \mathrm{~T} 6$ cells flatly attached to and completely spread on the prescribed samples, forming a very layer in which individual cells were distinguishable on both the pristine and implanted samples. Shown in Figure 5a-5b are two typical single cells on pristine $\mathrm{P}(\mathrm{HB}-\mathrm{co}-\mathrm{HH})$ samples and on $\mathrm{P}(\mathrm{HB}-\mathrm{co}-\mathrm{HH})$ samples implanted at the dose of $1 \times 10^{12}$ ions $\mathrm{cm}^{-2}$, whose MTT assay result was the best among its group. The cell adhered to the membrane with processes and multiple filopodia. The fibrillar bundles of extracellar matrix were attached to the materials and connected with cells. The fibroblast in Figure $5 \mathrm{~b}$ was fully out-stretched when compared with

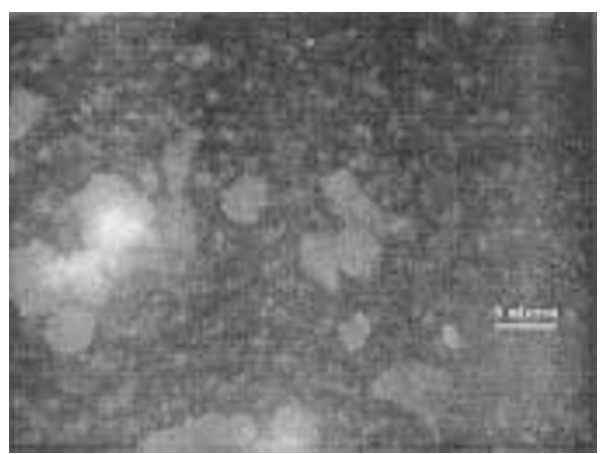

Figure 6. Fluorescence micrograph of PHB with $1 \times 10^{12}$ ions $\mathrm{cm}^{-2}$. Bar in the picture stands for $5 \mu \mathrm{m}$.

the one shown in Figure 5a and indicated the improved cytocompatibility.

The CLSM results show the three-dimensional 3T6 cell constructs. Figure $5 \mathrm{c}$ shows the example of the $24 \mathrm{~h}$ culture. The fibroblasts have integrity karyotheca.

The fluorescence microscopy observation of the cocultured $3 \mathrm{~T} 6$ cells on $\mathrm{P}(\mathrm{HB}-\mathrm{co}-\mathrm{HH})$ surfaces is shown on Figure 6. Compared to the pristine sample (not shown here), the density of cells is obviously improved. The cells are divided into two types: spindle shape and polygonal shape, which means in $24 \mathrm{~h}$ culture, the cells just grew from the adhere stage to the mature stage. This can also be clearly seen from the interior structure of cells in Figure 7. It indicated higher cell density and larger cell size on the samples with the ion implan- 


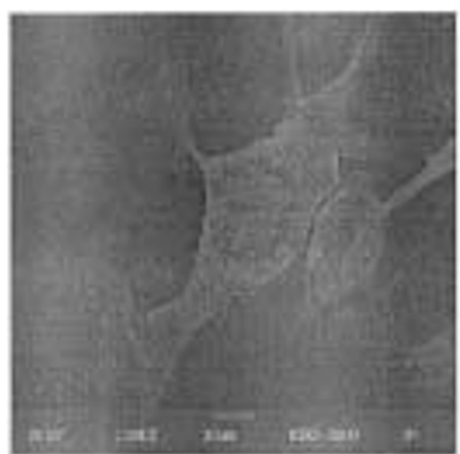

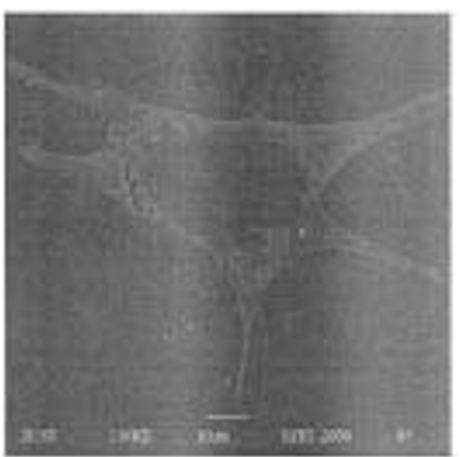

Figure 7. SEM micrographs of fibroblast adhering to (a) pristine $\mathrm{P}(\mathrm{HB}-c o-\mathrm{HH})$ sample surface and (b) samples with an ion implantation dose of $1 \times 10^{12}$ ions $\mathrm{cm}^{-2}$.

tation at a dose of $1 \times 10^{12}$ ions $\mathrm{cm}^{-2}$. The fibroblasts on the material spread their long filopodia, which are connected together nearby. And it is the former of the confluent cells.

Since no exact correlation between the cell density and the change mentioned above, we can come to the conclusion that the improvement of cytocompatibility was the result of several factors working together simultaneously.

\section{SUMMARY}

The surface composition, morphology and cytocompatibility of $\mathrm{PHB}, \mathrm{P}(\mathrm{HB}-\mathrm{co}-\mathrm{HV})$ and $\mathrm{P}(\mathrm{HB}-\mathrm{co}-\mathrm{HH})$ were all closely related to the ion doses. With increasing ion dose, hydronated carboneous layer was formed on the surfaces. The FTIR-ATR and XPS spectra all went through remarkable changes. The recovering of the changes in FTIR-ATR spectra when the samples were implanted with higher ion dose suggested that in high-dose implantation the newly formed carboneous layer might be the outmost layer that would be irradiated first. The XPS results showed that carbonyl group greatly decreased during the ion implantation. Only some small surface morphology changes took place, which indicates that under high ion dose has a smoothing effect on the prescribed samples. Cell culture experiment and morphology observation all suggested that there was a threshold around $1 \times 10^{12}$ and $1 \times 10^{13}$ ions $\mathrm{cm}^{-2}$ for PHB, P(HB-co-HV) and for $\mathrm{P}(\mathrm{HB}-\mathrm{HV})$ respectively.

Acknowledgment. We gratefully acknowledge the inspiring talk with Prof. Xuming Xie and Dr. Yiwei Fan and the laborious emendation taken by Mr. Lin Liu. This work is supported by the National Major Project of the Tenth-Five 863 Plan (2001-2005) of China (No. 2001AA216071).

\section{REFERENCES}

1. J. A. Alistair and A. D. Edwin, Microbiol. Rev., 4, 450 (1990).

2. F. R. Lang, D. Leonard, and H. J. Mathieu, Macromolecules, 31, 6177 (1998).

3. G.-Q. Chen, and Y. Deng, K. Zhao, "Biopolyesters-polyhydroxyalkanoates and Their Applications as Biomaterials", IUPAC World Polymer Congress, 39th International Symposium on Macromolecules, Beijing, Preprints 2002, Part 2, p 974.

4. X. Yang, K. Zhao, and G.-Q. Chen, Biomaterials, 23, 1391 (2002).

5. D. Flüsch, G. Clarotti, K. E. Gecheler, F. Schué, and W. Göpel, J. Membr. Sci., 73, 163 (1992).

6. S. Luo, A. N. Netravali, J. Appl. Polym. Sci., 73, 1059 (1999).

7. H. Dong and T. Bell, Surf. Coat. Technol., 111, 29 (1999).

8. D. M. Zhang, F. Z. Cui, Z. S. Luo, Y. B. Lin, K. Zhao, and G. Q. Chen, Surf. Coat. Technol., 131, 350 (2000).

9. J. Zhang, X. Ye, X. Yu, and H. Li, Mater. Sci. Eng., B, 84, 200 (2001).

10. E. H. Lee, G. R. Rao, M. B. Lewis, and L. K. Mansur, J. Mater. Res., 9, 1043 (1994).

11. M. Iwaki, Nucl. Instrum. Methods Phys. Res., Sect. B, 175, 368 (2001).

12. W. Liu, S. Yang, C. Li, and Y. Sun, Thin Solid Films, 323, 158 (1998).

13. S. Yang, S. Qi, W. Liu, C. Li, and Y. Sun, Wear, 211, 64 (1997).

14. M. Koto, K. Ohno, S. Yoshikado, K. Yukimura, S. Kurooka, Y. Suzuki, A. Kinomura, A. Chayahara, and Y. Horino, Mater. Chem. Phys., 127, 54 (1998).

15. Y. Suzuki, M. Kusakabe, M. Iwaki, K. Kusakabe, H. Akiba, and M. Suzuki, Mat. Res. Soc. Symp. Proc., 669, 110 (1989).

16. Y. Suzuki, M. Kusakabe, M. Iwaki, H. Akiba, and K. Kusakabe, Radiat. Phys. Chem., 553, 39 (1992).

17. Y. Suzuki, M. Kusakabe, H. Akiba, K. Kusakabe, and M. Iwaki, Nucl. Instrum. Methods Phys. Res., Sect. B, 698, B59/60 (1991).

18. Y. Suzuki, M. Kusakabe, J.-S. Lee, M. Kaibara, M. Iwaki, and H. Sasabe, Nucl. Instrum. Methods Phys. Res., Sect. B, 142, B65 (1992).

19. H. Tsuji, H. Satoh, S. Ikeda, N. Ikemoto, Y. Gotoh, and J. Ishikawa, Surf. Coat. Technol., 124, 103 (1998). 
20. H. Tsuji, H. Sato, T. Baba, A. Ikemura, Y. Gotoh, and J. Ishikawa, Nucl. Instrum. Methods Phys. Res., Sect. B, 815819, B166-167(2000).

21. G. Zund, Q. Ye, S. P. Hoerstrup, A. Shoeberlein, A. C. Schmid, J. Grunenfelder, P. Vogt, and M. Turina, Eur. J. Cardio-thorac. Surg., 15, 519 (1999).

22. G. Ciapetti, E. Cenni, L. Pratelli, and A. Pizzoferrato, Biomaterials, 14, 359 (1993).

23. P. Boargatti, A. M. Martelli, A. Bellacosa, R. Casto, L. Massari, S. Capitani, and L. M. Neri, Federation of European Biochemical Societies, 477, 27 (2000).

24. E. H. W. Pap, G. P. C. Drummen, V. J. Winter, T. W. A. Kooij, P. Rijken, K. W. A. Wirtz, J. A. F. Opdenkamp, W. J. Hage, and J. A. Post, Federation of European Biochemical Societies, 453, 278 (1999).

25. D. S. Synder and P. L. C. Small, J. Immunol. Methods, 257, 35 (2001).

26. H. Q. Zhang and M. L. Lian, "Cell Biology Experiment Meth- ods and Technologies", Beijing Normal University Press, Beijing, 1992, p 29.

27. R. U. A. Khan and S. R. P. Silva, Diamond Relat. Mater., 10, 224 (2001).

28. B. Pignataro, E. Conte, A. Scandurra, and G. Marletta, Biomaterials, 18, 1461 (1997).

29. C. Satriano, E. Conte, and G. Marletta, Langmuir, 17, 2243 (2001).

30. C. J. Sofield, S. Sugden, and J. Ing, Vacuum, 44(3/4), 285 (1993).

31. D. Tsoukalas, Solid-State Electron., 33, 639 (1990).

32. A. Mas, H. Jaaba, and F. Schue, J. Macromol. Sci., Pure Appl. Chem., A, 34(1), 67 (1997).

33. D. Briggs, "Surface Analysis of Polymers by XPS and Static SIMS”, Cambridge University Press, New York, N.Y., 1998, p 50 .

34. J. Zhang, Q. Wu, X. Yu, P. Zha, and H. Li, Phys. Status Solidi $A$, 186, 47 (2001). 